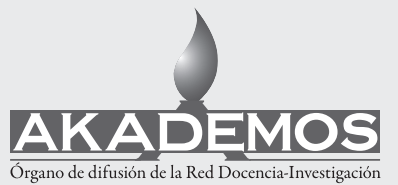

ISSN: $1995-4743$

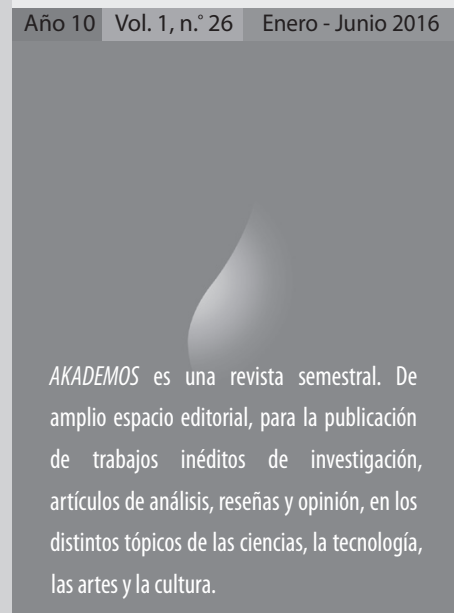

San Salvador, El Salvador, Centroamérica
En el mundo de la ética, ¿se considera la posmodernidad un paso adelanto o un retroceso?

\title{
El èthos posmoderno o la moral del nómada. Estudio sobre la condición moral en la posmodernidad
}

\author{
David E. López \\ Investigador Centro de Investigaciones en Ciencias y Humanidades, $\mathrm{CICH}$. \\ davidelopez@hotmail.com
}

Fecha de recepción 18/05/2016 • Fecha de aceptación 31/05/2016

\section{Abstract}

Posmodernity can be thought as an èthos, that is to say, it could be viewed as a way of being or as a moral character. This way of being could be featured, on the one hand, as something leaving aside the modern point of view and due to its incredulity in utopies, and, on the other hand, by raising of a new èthos: a moral life without restrictions and regulations, an invalidity of ideas in regulation or cathegorical imperatives of worldwide worth, a worship to diversity and plurality, a refusing to any bistorical project, an axiological relativism and subjectivism, a freedom of sexual intercourse of any traditional moral compulsion, an encouragement of superficial, liquid and ephemeral interpersonal re- lationships. All these things raise disenchantment and dissatisfaction. Claiming this point of view and celebrating it as breaking the chains of oppression or as the non plus ultra of bistory means being postmodern. When we study this postmodern condition we can not circumscribe ourselves to a mere description, but we ought to explain it and propose a new èthos.

\section{Resumen}

La posmodernidad debe ser considerada, ante todo, como un èthos, es decir, como un modo de ser o un carácter moral que se caracterizaría, de una parte, por un abandono 
de la perspectiva moderna y por la incredulidad en su proyecto utópico y, de otra, por la emergencia de un nuevo èthos: una vida moral sin normas ni regulaciones, la invalidez de ideas reguladoras y de valor universal, el culto a la pluralidad y a la diversidad, el rechazo a la idea de proyecto histórico, el relativismo y el subjetivismo axiológicos, la liberación de la actividad sexual de las compulsiones morales tradicionales y el fomento de relaciones interpersonales superficiales, líquidas y transitorias, las que generan pronto desencanto y frustración. Sostener este punto de vista y festejarlo como la liberación de las cadenas de la opresión o como el non plus ultra de la historia es ser posmoderno. El estudio de esta condición no puede limitarse, no obstante, a describir el modo de ser posmoderno; sino que debe explicarla y proponer un nuevo èthos.

Palabras claves: êthos, ética, moral, modernidad, posmodernidad, carácter, hábito, virtud, metarrelato, utopia

Key words: èthos, ethics, moral, modernitity, posmodernity, character, habit, virtue, metanarrative, utopia

\section{Introducción}

Una de las características culturales más notorias de nuestro tiempo consiste en los cambios en la moral de las personas con respecto a épocas precedentes. Estos cambios han mostrado durabilidad, resistencia y masividad, por lo que no pueden ser considerados ya como algo pasajero o de moda, sino como un cambio cultural, de costumbres.
El estudio de estas nuevas prácticas morales -lo que suele ser llamado moral-es tarea de la ética o filosofía moral. Pero una filosofía moral no puede limitarse a describir la conducta de los individuos; por el contrario, debe ofrecer una explicación de la misma y orientar la acción o indicar posibles caminos a seguir.

Lo anteriormente mencionado es lo que pretende hacerse en este estudio, en el cual se procede inicialmente al debate conceptual en torno a la idea de ética y de moral, para luego pasar al objeto específico de nuestro estudio: el èthos posmoderno.

\section{Primera parte: ¿qué es la ética?}

\section{Sobre la etimología de ética}

Iniciamos nuestro estudio por una breve indagación sobre la etimología de ética y moral. Según López Aranguren (1998, p. 21), la investigación etimológica de términos complejos tiene la ventaja de que "nos devuelve la fuerza elemental de las palabras originarias, a las que es menester regresar para recuperar su sentido auténtico".

Sigamos, luego, el sabio consejo de este gran filósofo español del siglo XX. El sustantivo femenino griego ética ( $\boldsymbol{\eta} \theta \mathbf{u} \boldsymbol{x} \boldsymbol{\alpha}$, èthika) procede del sustantivo masculino èthos ( $\tilde{\boldsymbol{\eta}} \theta \mathbf{o s}$, èthos). Este último posee los siguientes significados:

i) Su significado más antiguo es residencia, morada o lugar donde se habita (López Aranguren, 1998, p. 21). Por su parte, 
Liddell, \& Scott, (1966, p. 766) afirman que el significado más antiguo podría traducirse como lugar habitual (accostumed place); cuando el término se refiere específicamente a animales, este indica guarida o cueva. Por su parte, Hesiodo y Heródoto usan esta palabra referida específicamente a morada o residencia de seres humanos.

ii) Referido a seres humanos o a pueblos, el vocablo indica el suelo firme, el fundamento de la praxis, la raíz de la que brotan todos los actos humanos (López Aranguren, 1998).

iii) Desde Aristóteles, ethos significa modo de ser o carácter, "modo o forma de vida que se va adquiriendo", anota López Aranguren (1998, p. 22); carácter o costumbre en sentido moral, anotan Liddell \& Scott (1966, p. 766). Este carácter, para Aristóteles, se adquiere como resultado del hábito; según él, existen dos tipos de virtudes: las dianoéticas, intelectuales, que se adquieren mediante la enseñanza, y las éticas, morales, que proceden de la costumbre:

Además, de todas las disposiciones naturales, adquirimos la capacidad y luego ejercemos las actividades. Esto es evidente en el caso de los sentidos; pues no por ver muchas veces y oír muchas veces adquirimos los sentidos, sino al revés: los usamos porque los tenemos, no los tenemos por haberlos usado. En cambio, adquirimos las virtudes como resultado de actividades anteriores. Y este es el caso de las demás artes, pues lo que hay que hacer después de haber aprendido, lo aprendemos haciéndolo. Así nos hacemos constructores construyendo casas, y citaristas tocando la cítara. De un modo semejante, practicando la justicia nos hacemos justos; practicando la moderación, moderados, $\mathrm{y}$ practicando la virilidad, viriles. (...) (Aristóteles, 1985, pp. 158-59)

El sustantivo èthos está familiarizado con éthos ( $\boldsymbol{\varepsilon} \boldsymbol{\theta} \mathbf{o} \boldsymbol{s}$, éthos, esta vez con $\boldsymbol{\varepsilon}$, epsilon), el cual significa costumbre o hábito, uso que encontramos ya en Platón y en Aristóteles, como lo refieren Liddell, H. G. \& Scott, R. (1966, p. 479). Por tal vocablo se entiende, entonces, lo que los latinos llamaban habitus. Pero en griego tenemos otro sustantivo que significa hábito, se tra-

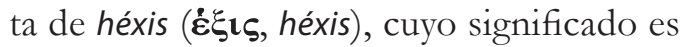
"tener algo en posesión, lo que uno posee, hábito o habilidad adquiridos" mediante la praxis Liddell \& Scott (1966, p. 595). Tanto habitus, del verbo latino habere; como héxis, del verbo griego ēcho, derivan del verbo poseer o haber, y se refiere a algo que se llega a adquirir mediante la práctica.

López Aranguren (1998) afirma que héxis, en sentido moral, se refiere al hábito que adquirimos o llegamos a poseer, en el sentido de un modo de comportarnos, bien sea este con base a la virtud o al vicio. En este sentido, el significado de héxis es más preciso que èthos, del que es sinónimo en sentido amplio.

Una manera más actual y precisa de entender el hábito es la que nos ofrece Bilbeny (1997, p. 54): 
El hábito es un modo de obrar adquirido por repetición de un acto. Mediante aprendizaje introduce pues una cierta regularidad en nuestro comportamiento, que es la fuerza y la gracia de la ética. (...)

Veamos ahora cómo López Aranguren (1998, p. 22) refiere la tríada que explica lo moral en sentido etimológico: hay un círculo formado por èthos (荀os, èthos), carácter

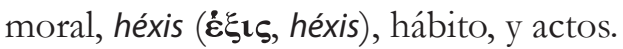

En resumen, López Aranguren (1998) afirma que los hábitos (héxis, o su sinónimo éthos) constituyen el principio intrínseco de los actos, y que el êthos es el carácter, acuñado o impreso en la persona por medio del hábito; en otras palabras, el èthos es el carácter y la fuente de los actos. Se trata, luego, de algo adquirido mediante la práxis, no de un don de la naturaleza. Por eso varios teóricos aseguran que el èthos consiste en un modo de ser o carácter que se convierte en una segunda naturaleza del ser humano, cuando lo adquiere. En otras palabras, el êthos no se origina en la naturaleza humana, sino que tiene un origen socio-cultural; aunque no es reductible a una herencia puramente social y cultural, como pensaron algunos estudiosos, sobre todo Durkheim.

Una de las debilidades de la moral clásica y moderna, refiere López Aranguren (1998), es el haberse ocupado de los actos morales y de los hábitos -virtudes y vicios-, pero no del èthos.

En latín tenemos una sola palabra para traducir êthos y éthos, y esta es el sustantivo masculino mōs, mōris; plural: mōres. Esta palabra tiene el sentido general de "costumbre, norma moral, carácter o modo de ser". Así, de una persona que vive en desacuerdo con las normas morales socialmente aceptadas se dirá que es alguien que vive sine more, esto es, vive desenfrenadamente o de manera inmoral (Mir, 1990, p. 309). De esta manera, lo que los griegos llamaban èthos, los latinos lo llaman mōs; pero ambos términos significan básicamente lo mismo: modo de ser o carácter, en sentido moral.

López Aranguren (1998) expresa el sentido moral de esos sustantivos grecolatinos de esta manera: la tarea moral del ser humano consiste en la adquisición de un modo de ser. ¿Cómo se adquiere este modo de ser? Para el autor esto se da en tres niveles de apropiación. En el primer nivel está lo que él llama páthos, siguiendo la etimología griega, el cual consiste en el nivel de apropiación de los sentimientos, que tienen poco valor moral, debido, sobre todo, a que los mismos no dependen de la voluntad del sujeto. En el segundo nivel de apropiación están las costumbres que significan un grado más alto de apropiación por parte del sujeto. En el tercer nivel, por último, tenemos el carácter, y este consiste en una impresión de rasgos en el sujeto o, en otras palabras, el carácter es la personalidad que se ha conquistado a través de la vida, lo que se ha hecho de uno mismo viviendo.

Bilbeny (1997) plantea lo anterior de una manera ligeramente diferente a la de López Aranguren: lo que se obtiene con un hábito, el estado o condición que procura, es la 
disposición a actuar en un sentido u otro. Así, continúa, el hábito nos dispone a actuar según una vieja o una nueva costumbre, una común o una singular norma de conducta.

Bilbeny (1997, p. 61) sostiene que los primeros hábitos y creencias del individuo son indesligables del contacto con su familia:

Los hábitos y creencias están ligados a nuestra percepción de la realidad. (...) Esta percepción, desde los primeros días de vida del individuo, se hace a través de la sensibilidad: los primeros hábitos y creencias son indesligables del contacto con los progenitores. Esta acomodación a la experiencia sensorial prevalece a lo largo de la vida.

\section{El objeto material de la ética}

López Aranguren (1998, p. 133) resume de esta manera el objeto de la ética:

Se suele definir la ética como la parte de la filosofía que trata de los actos morales, entendiendo por actos morales los medidos o regulados por la regula morum [regla de la moral]. De tal modo que el objeto material de la ética serían los actos humani (a diferencia de los actos hominis); es decir, los actos libres y deliberados (perfecta o imperfectamente). Y el objeto formal, estos mismos actos, considerados bajo la razón formal de su ordenamiento por la regula morum.

Sánchez Vásquez (1984, p. 26), por su parte, sostiene que el objeto de la ética es como sigue: "Su objeto de estudio lo constituye un tipo de actos humanos: los actos conscientes y voluntarios de los individuos que afectan a otros, a determinados grupos sociales, o a la sociedad en su conjunto".

Para Sánchez Vásquez, a diferencia de López Aranguren, el objeto material de la ética es más reducido: los actos humanos (actus humani), añadiendo que se trata de actos conscientes y voluntarios -lo que otras tradiciones filosóficas llamarán actos libresy que afectan a los demás. López Aranguren (1998, p. 135), en cambio, piensa que el objeto es más amplio, cuando afirma que la ética "(...) debe ocuparse fundamentalmente del carácter, modo adquirido de ser o inclinación natural ad agendum; y puesto que este carácter o segunda naturaleza se adquiere por el hábito, también de los hábitos debe tratar la Ética".

Más adelante, el autor hace una ulterior precisión: "El objeto material de la Ética parece, pues, constituido por el carácter (ēthos), los hábitos y los actos humanos. (...)" (López Aranguren, 1998, p. 141)

Para este autor, en consecuencia, hay una conexión o un círculo entre los conceptos de modo ético de ser, hábitos y actos. La razón de ello es la siguiente: el modo de ser sustenta los hábitos y estos son los principios intrínsecos de los actos; a su vez, refiere López Aranguren (1998, p. 135), "los hábitos se engendran por repetición de actos y el modo ético de ser se adquiere por hábito".

¿Qué tipo de actos son los que considera la ética? El autor trae a la memoria la dis- 
tinción escolástica entre actos del hombre (actus hominis), es decir, las acción humana natural, y los actos humanos (actus humani), a saber, los actos libres y deliberados. Estos últimos, refiere, son propiamente el objeto de la Ética. En definitiva, dirá el autor (López Aranguren, 1998, p. 145), el objeto material de la ética "consiste fundamentalmente en el èthos, esto es, en la personalidad moral; pero que la personalidad moral se define a través de todos y cada uno de los actos y de los hábitos, por lo cual estos no pueden ser relegados a un segundo término al hablar de objeto de la ética".

\section{Sobre el objeto formal de la ética}

Cuando hablamos de objeto formal de la ética nos referimos a la perspectiva desde la cual aborda su objeto material -el èthos, la hexis y los actos-, esto es, el punto de vista (objeto formal) desde el que estudia su tema o contenido. En el caso de la ética, esa perspectiva es el estudio de la acción humana en cuanto buena o mala o, en otras palabras, su objeto formal es el estudio de la acción humana desde el punto de vista de su bondad o su maldad. La acción humana, como sabemos, es objeto de estudio (objeto material) de diversas disciplinas; pero lo específico de la ética es el modo de tratar esta acción. ${ }^{1}$

A este respecto, López Aranguren (1998, p. 148) afirma que el objeto formal de la ética es "el bien moral, es decir, los «actos, hábitos, vida, èthos, en cuanto buenos (o malos)»". En otras palabras, se estudian los actos en cuanto buenos o malos; los hábitos en cuanto virtudes o vicios; y las formas de vida desde el punto de vista moral (López Aranguren 1998).

Lo anterior nos conduce a uno de los problemas más difíciles de la teoría moral, y es el debate y la respuesta a la pregunta ¿qué es el bien? López Aranguren (1998) refiere la respuesta que dan Aristóteles y Santo Tomás: el bien es lo que todos los hombres apetecen. Todo lo que hacemos, continúa, lo hacemos desde un agathón (bien), con vistas a un fin.

A estas alturas resulta obvio que una tarea fundamental de una filosofía moral es determinar qué es el bien. $\mathrm{Y}$ aquí entra propiamente el debate ético: ¿es el bien determinable de una vez por todas o es algo que puede variar históricamente?, ¿existe algún bien absoluto y universal, o solo hay bienes particulares?; ¿dónde reside la bondad del bien?, ¿en el sujeto?, ¿en la acción?, ¿en los fines de la acción?, ¿en los motivos de la acción?

Además de lo anterior, aquí viene el problema de para qué una reflexión ética debe definir el bien: ¿para decir a los demás lo que deben hacer y lo que tienen que evitar?, ¿para indicar un posible camino de la acción humana éticamente considerada?

Por otra parte, cabe preguntarse si esa perspectiva de la ética en el abordaje de su ob-

1 El acto moral, nos dice Bauman, "en sí es endémicamente ambivalente, por siempre hilando precariamente los finos hilos que dividen el cariño de la dominación, y la tolerancia, de la indiferencia”. (Bauman, 2005, pág. 207). Y continúa: "Las consecuencias del acto son forzosamente ambivalentes". 
jeto puede ser simplemente una descripción de la realidad moral, esto es, la ética sería un saber empírico que no prescribe sino que explica, describe e indica la acción humana; o, por el contrario, la ética no parte de la realidad empírica de la vida moral, sino que su teoría se funda en un razonamiento deductivo, y, en este sentido, tendría un carácter a priori, no empírico, al estilo del imperativo categórico de Kant.

Con respecto a lo anterior, Sánchez Vásquez (1984) expone que muchas teorías han girado en torno a la definición de lo bueno, en el supuesto de que si sabemos determinar lo bueno, podremos saber qué debe hacerse o no. Las respuestas varían, según la tradición filosófica: la felicidad, lo útil, el placer, el poder, la autorrealización, etc.

Junto a lo anterior, Sánchez Vásquez piensa que hay otra tarea de la ética en cuanto a su objeto formal, y esta es como sigue: es tarea de la ética definir los rasgos esenciales del comportamiento moral (este es uno de los grandes problemas del ethos posmoderno, del que mejor deberíamos hablar de ethoi posmodernos). En otras palabras, la ética debe definir el problema de la esencia del acto moral, y esto nos relaciona inmediatamente con otro: el de la responsabilidad. Y el problema de la responsabilidad remite a otro: solo se puede hablar de comportamiento moral cuando el sujeto es responsable de sus actos, y esto nos lleva al problema de si el sujeto ha podido elegir entre varias alternativas, y actuar de acuerdo a la decisión tomada. Esto es el problema de la libertad de la voluntad, que es inseparable de la responsabilidad.
En cuanto a la determinación del bien, Aristóteles lo define como la felicidad (eudaimonía), pero lo define como modo de ser, como èthos (López Aranguren, 1998, p. 176).

López Aranguren (1998) afirma que el acto humano es interior y exterior. El objeto del acto interior es el fin (finis operantis, [fin del que actúa o del sujeto/agente]). El objeto de la acción en cuanto tal es el finis operis ([fin de la acción o del acto]). Los actos humanos, continúa, se especifican moralmente por el fin que, al ejecutarlos, movió a su autor. El fin da o quita bondad, pero por modo extrínseco. Más exactamente esto quiere decir lo siguiente:

(...) si el finis operantis es malo, convierte al acto en malo, aunque por su objeto fuese bueno. (...) Si, por el contrario, el finis operantis es bueno, puede convertir un acto malo por su objeto en bueno - pero solo subjetiva y extrínsecamente bueno. (...) (López Aranguren, 1998, p. 200)

\section{Problemas éticos y problemas morales}

En el lenguaje común se suele hacer un uso indiferenciado de los conceptos de ética y de moral, pero si somos más rigurosos con los conceptos debemos utilizarlos de manera diferenciada, esto es, ambos cubren campos distintos y diferentes; pero relacionados.

Con respecto a esta diferenciación, López Aranguren (1998) habla de ethica docens [ética que se enseña] para referirse a la teoría filosófica de la moral; lo que otros simplemente 
llaman ética; en cambio, para tratar a la vida moral práctica prefiere usar la locución ethica utens [ética que se usa o se practica], a lo que suele darse más el nombre de moral o moral vivida. $\mathrm{El}$ autor aclara que la ethica docens no crea èthos, sino que se limita a filosofar sobre él; en otras palabras, una filosofía moral no crea una práctica moral. Las preguntas razonables que surgen son las siguientes: ¿para qué, entonces, sirve la ética?, ¿cómo se crea el êthos? En la segunda parte de esta investigación abordaré este problema.

Sánchez Vásquez (1984, p. 19), por su parte, sostiene que "el comportamiento prácticomoral" es común a todas las sociedades, y "se remonta a los orígenes mismos del hombre como ser social"; además de darse hasta en las formas más primitivas de sociedad, como Durkheim lo sostuvo mucho antes. A este comportamiento es a lo que él llama moral.

Posterior al comportamiento moral, agrega Sánchez Vásquez, surge la reflexión acerca de este fenómeno. En este sentido, sostiene, los hombres no solo actúan moralmente actúan, toman decisiones, juzgan, valoran, etc.-, sino que, agrega, reflexionan sobre ese comportamiento. De esta manera, piensa, se pasa del plano de la moral práctica al de la teoría. Este paso, como sabemos, se da con los griegos, con quienes se inicia la reflexión filosófica; a partir de este momento, en consecuencia, se inicia el debate de los problemas teóricos de la moral o, en otras palabras, de los problemas éticos. Encontramos huellas visibles de esta reflexión en los sofistas y en Sócrates, en el siglo $V$ a.C. En resumen, lo primero en aparecer en la socie- dad es la vida moral y, muchísimo tiempo después, surge la teoría moral.

Para Sánchez Vásquez (1984), se debe diferenciar entre problemas éticos y problemas morales. Esto puede establecerse de la siguiente manera: a) los problemas éticos se caracterizan por su generalidad, mientras que los morales son de la vida cotidiana y se plantean problemas de situaciones concretas; aunque la ética, reconoce, puede contribuir a fundamentar o justificar cierta forma de comportamiento moral. El autor nos propone un ejemplo de esto último: "si la ética descubre una relación entre el comportamiento moral y las necesidades e intereses sociales, esto nos ayudará a poner en su verdadero lugar la moral efectiva de ciertos grupos sociales" (Sánchez Vásquez, 1984, p. 21); b) la ética o teoría moral puede decir lo que es una conducta sujeta a normas o en qué consiste el bien que debe perseguir la conducta moral, pero únicamente la moral puede decir lo que se debe hacer en la vida real concreta; en otras palabras, la ética no es normativa, mientras que la moral sí lo es; c) la ética no puede decir qué hacer en una situación concreta, la moral sí; d) la ética puede definir qué es lo bueno o el fin de la acción, pero esto no lo puede hacer la moral.

Aquí tenemos el resumen de estas diferencias que hacer el autor:

“(...) El problema de qué hacer en cada situación concreta es un problema práctico-moral, no teórico-ético. En cambio, definir qué es lo bueno no es un problema moral que corresponda resolver a un individuo con respecto a cada caso particular, sino un 
problema de carácter teórico que toca resolver al investigador de la moral, es decir, al ético. Así, por ejemplo, Aristóteles se plantea, en la Antigüedad griega, el problema teórico de definir lo bueno. Su tarea es investigar el contenido de lo bueno, y no determinar lo que el individuo debe hacer en cada caso concreto para que su acto pueda considerarse bueno. Cierto es que esta investigación teórica no deja de tener consecuencias prácticas, pues al definirse qué es lo bueno se está señalando un camino general, en el marco del cual, los hombres pueden orientar su conducta en diversas situaciones particulares. En este sentido, la teoría puede influir en el comportamiento moral-práctico. Pero, ello no obstante, el problema práctico que el individuo tiene que resolver en su vida cotidiana, y el teórico que el investigador ha de resolver sobre la base del material que le brinda la conducta moral efectiva de los hombres, no pueden identificarse. (...)” (Sánchez Vásquez, 1984, p. 20)

En definitiva, dirá el autor, “(...) la tarea fundamental de la ética es la de toda teoría: o sea, explicar, esclarecer o investigar una realidad produciendo los conceptos correspondientes. Por otro lado, la realidad moral varía históricamente, y con ella sus principios y normas. (...)" (Sánchez Vásquez, 1984 , p. 22). En esta misma dirección apunta Bauman (2005, p. 2), quien suele usar los términos de práctica moral, para referirse a la acción moral; y ética o teoría moral, para referirse a la reflexión filosófica.

Al final de sus indagaciones, cada estudioso nos ofrece su idea de ética. Sánchez Vás- quez (1984, p. 25) la define así: "La ética es la teoría o ciencia del comportamiento moral de los hombres en sociedad. O sea, es ciencia de una forma específica de conducta humana".

Una noción relativamente diferente a las anteriores es la que nos ofrece Nicola Abbagnano (1989). Según este gran filósofo de Turín, existen dos concepciones fundamentales de esta "ciencia de la conducta". La primera de ellas sostiene que la ética se centra en el fin al que debe dirigirse la acción humana y en los medios para obtener tal fin. La ética de Platón es parte de esta concepción, pero el prototipo sería la ética de Aristóteles, cuya tarea es determinar el fin de la conducta humana (la felicidad, endaimonía), la que es deducida de la naturaleza racional del hombre. A este tipo de éticas otros autores le llaman ética teleológica, a saber, centrada en el télos o fin. Esta ética suele insistir en el ideal que guía la acción humana y en los medios para su consecución.

La segunda concepción de la ética que resume Abbagnano es aquella que se centra en el impulso de la conducta humana y, a su vez, trata de determinarlo con vistas a dirigir o disciplinar la conducta. El bien, en esta ética, no es un ideal o un fin, sino la voluntad humana y el móvil o motivo de la acción. Esta ética insiste en el motivo de la acción. El imperativo categórico de Kant es el ejemplo más sobresaliente de este modo de entender la acción. A este tipo de teorías se les suele conocer con el nombre de ética deontológica, del griego deón, deber.

Una crítica que puede hacerse a Sánchez Vásquez es esta: él considera que la ética es una 
disciplina empírica, y lo dice con estas palabras: “(...) La ética es teoría, investigación o explicación de un tipo de experiencia humana, o forma de comportamiento de los hombres, el de la moral, pero considerado en su totalidad, diversidad y variedad. (...)" (Sánchez Vásquez, 1984, p. 23). Si esto fuera así, no sería ética una de las teorías morales más geniales que se conoce: la del imperativo categórico kantiano que, a todas luces, no es un estudio empírico, sino una teoría a priori de la moral. Kant rechaza expresamente la deducción de las normas morales de la experiencia. Considerar la ética como una "investigación de la experiencia humana", o de "la forma de comportamiento de los hombres" es un empirismo ético redivivo. Debemos aclarar, no obstante y para ser justos con el autor, que este no considera la ética como una rama o parte de la filosofía, sino como una ciencia y, en este sentido, podría entenderse que insista en el carácter explicativo de la realidad empírica moral como tarea de la ética.

Una manera más actual de entender la diferencia entre problemas éticos y problemas morales podría ser la siguiente: cuando hablamos de ética nos referimos al discurso ético y cuando nos referimos a moral nos referimos a la prácti$c a$. La línea divisoria entre ambas dimensiones no siempre está claramente trazada.

\section{Segunda parte: el èthos posmoderno}

\section{El concepto de posmodernidad}

El concepto de posmodernidad ${ }^{2}$ señala un aspecto de la sociedad contemporánea: el momento filosófico y cultural. Según J. F.
Lyotard (1991), por posmodernidad debemos entender un estado de la cultura, marcado por la incredulidad respecto a los metarrelatos, donde el saber se convierte en un instrumento de poder y, además, donde hay una separación entre el saber y la formación.

El texto de Lyotard anteriormente citado data de 1979, pero en uno más reciente aclara lo anterior:

Los "metarrelatos" a que se refiere La condición posmoderna son aquellos que han marcado la modernidad: emancipación progresiva de la razón y de la libertad, emancipación progresiva o catastrófica del trabajo (fuente de valor alienado en el capitalismo), enriquecimiento de toda la humanidad a través del progreso de la tecnociencia capitalista, e incluso, si se cuenta al cristianismo dentro de la modernidad (opuesto, por lo tanto, al clasicismo antiguo), salvación de las creaturas por medio de la conversión de las almas vía el relato crístico del amor mártir. La filosofía de Hegel totaliza todos estos relatos y, en este sentido, concentra en sí misma la modernidad especulativa. (Lyotard, J. F., 1994, p. 29)

Estos relatos, añade el autor, no son mitos en el sentido de fábulas; pero tienen la mis-

2 El concepto de posmodernidad lo he abordado, y su relación con el de globalización, lo he abordado con mayor amplitud en mi López, D. E. (2015). La construcción histórica de la educación superior. Modelos universitarios y docentes. Antiguo Cuscatlán: Centro de Investigaciones en Ciencias y Humanidades (CICH), Universidad Dr. José Matías Delgado (UJMD). 
ma finalidad: legitimar las instituciones y las prácticas sociales y políticas, las legislaciones, las éticas, las maneras de pensar. Pero, añade, a diferencia de los mitos estos metarrelatos no establecen la legitimidad en un acto originario fundacional (una especie in illo tempore mítico), sino en el futuro que se ha de producir, es decir, en una idea a realizar, la cual adquiere diferentes nombres: libertad, luz, socialismo, comunismo, etc. Esta idea tiene un valor legitimante porque es universal. Por eso mismo la idea orienta todas las realidades y las acciones humanas, y da a la humanidad, continúa Lyotard, su sentido característico: el de proyecto (Lyotard, 1994, p. 30).

Si bien es cierto que la modernidad no se legitima en un mítico pasado remoto, en una especie de edad de oro al inicio de la historia, como sucede en Hesiodo; su idea de un futuro luminoso, de un reino de los fines, de un Estado absoluto o de un comunismo pueden ser considerados como ideas míticas. La idea del comunismo de Marx es más evidente en este sentido. Con respecto a esta concepción mítica de idea de Marx, Eliade (1980, p. 137) afirma que la idea de comunismo al final de la historia es una especie de nueva edad de oro, asimismo su idea de que la historia camina indefectiblemente hacia el progreso y la plenificación humana; todo esto, para el gran estudioso de los mitos y de las ideas religiosas, es una estructura mítica, solo que Marx coloca "el mito de la edad de oro al final de la historia, y no al principio de la misma, como lo hacía el pensamiento arcaico". Luego, entonces, no parece válida la afirmación de que la modernidad no se le- gitima en mitos, sino en la idea de proyecto. El proyecto mismo de la modernidad delata estructuras míticas, como lo sugiere Eliade en el caso del comunismo.

Al criticar este aspecto central de la modernidad -la idea de vivir con un proyecto-, Bauman (2005, p. 259) afirma lo siguiente:

La felicidad futura sirvió de pantalla para la repulsión del presente. La Gran Idea le imprimió al sufrimiento un significado moderno y novedoso, del que se eliminó el antiguo sentido del desmantelamiento del Paraíso. (...)

Para el autor, no obstante, ese proyecto moderno -que él llama también realización de la universalidad - no ha sido abandonado ni olvidado, sino liquidado y destruido, esto es, el proyecto de la modernidad dejó de existir. Los metarrelatos, para Lyotard, legitimaban esa modernidad, pero ¿qué entiende el autor por metarrelato?

(...) Por metarrelato o gran relato, entiendo precisamente las narraciones que tienen función legitimante o legitimatoria. Su decadencia no impide que existan millares de historias, pequeñas o no tan pequeñas, que continúen tramando el tejido de la vida cotidiana (Lyotard, 1994 p. 31).

Lyotard (1994) afirma que el pensamiento y la acción de los siglos XIX y XX están dominados por la idea de la emancipación. Esta idea se argumenta en todas las filosofías de la historia: el relato cristiano de la redención, el relato de la Ilustración y su emancipación 
de la ignorancia y la servidumbre, el relato especulativo de la realización de la idea universal por la dialéctica de lo concreto, el relato marxista de la emancipación de la explotación y de la alienación, el relato capitalista de la emancipación de la pobreza por el desarrollo tecnoindustrial. Todos estos relatos difieren entre sí, pero están de acuerdo entre sí en lo siguiente:

(...) todos ellos sitúan los datos que aportan los acontecimientos en el curso de una historia cuyo término, aun cuando ya no quepa esperarlo, se llama libertad universal absoluta de toda la humanidad (Lyotard, 1994, p. 36).

Con la ayuda de Mèllich ampliaremos el concepto de posmodernidad. Según este autor, el origen de esta condición filosófica y cultural puede plantearse así: "La postmodernidad nace en el instante en que una única verdad se descompone en cientos de verdades relativas que los hombre se reparten (...)" (Mèllich, 2008, p. 35).

En la posmodernidad, en otras palabras, parece no quedar "nada estable ni definitivo", sostiene Mèllich, y ejemplifica ello diciendo que no queda ni sustancia, ni Dios, ni razón, ni sujeto.

La educación es particularmente afectada por la posmodernidad, puesto que "ya no se encuentran reglas de formación en un mundo transcendente", y la educación es una actividad humana que necesita de estas reglas. El autor expresa esta situación en términos muy escalofriantes: "La vida hu- mana se queda sin rumbo fijo, sin un horizonte que le sirva de punto de referencia". (Mèllich, 2008, p. 35)

Además de lo anteriormente expresado, Mèllich refiere que con la posmodernidad la vieja metafísica, de corte platónico, ha llegado a su fin. ¿Qué queda en lugar de esa filosofía? El gran estudioso catalán responde: "ya sólo quedan narraciones que no se sostienen sobre un horizonte de absoluta inteligibilidad y sentido" (Mèllich, 2008, p. 35)3.

Dentro de este nuevo horizonte cultural surgiría también un nuevo pensamiento filosófico, la así llamada filosofía posmoderna, que Mèllich define como "aquella que no cree que exista ningún 'punto arquimédico' del conocimiento o de la moral que permita construir un sistema" (Mèllich, 2008, p. 35). En otras palabras, para la filosofía posmoderna no existen puntos fijos en el conocimiento, ni verdades morales fundamentales, ni mucho menos verdades absolutas; pero tampoco existen valores absolutos, como la vida humana y el respeto a la misma, que la tradición ha consagrado; mucho menos reconoce horizontes últimos o normas morales absolutamente válidas, como la idea kantiana del imperativo categórico, que Kant consideraba válido para todo ser racional. Contrario a todo esto, la filosofía posmoderna sostiene la relatividad de todo conocimiento y de toda moral. Todo es relativo. Méllich expresa esto de la manera si-

3 Las cursivas son del autor. 
guiente: "Para ella solo hay historias, relatos, juegos, interpretaciones" (Mèllich, 2008, p. 35) ${ }^{4}$.

¿Cuándo y cómo se gesta la posmodernidad? Según este investigador, la crisis de la filosofía moderna y la irrupción de la época posmoderna pueden entenderse a través de varios pensadores: F. Nietzsche (1844-1900), M. Heidegger (1889-1976), H. G. Gadamer (1900-2002) y R. Rorty (1931-2007), entre otros.

Dentro de los autores arriba mencionados, quizás sea la filosofía de Nietzsche, conocida como nibilismo, la que más contribuyó al proceso de gestación de la posmodernidad, con su crítica demoledora de la filosofía clásica -específicamente del platonismo- y del Cristianismo, con lo cual socava teóricamente los fundamentos en los que se asienta la civilización occidental. Por eso nos detendremos a examinar algunas ideas de este gran filósofo alemán, a quien Paul Ricoeur nombró como uno de los tres maestros de la sospecha (los dos restantes son ni más ni menos que K. Marx y S. Freud). En la exposición nos dejaremos guiar por las ideas de Mèllich sobre este pensador.

Según Mèllich, "el umbral filosófico entre la modernidad y la postmodernidad lo descubrimos en la obra de Nietzsche" (Mèllich, 2008, p. 36). En el padre del nihilismo encontraríamos la crítica más severa jamás expresada a la metafísica: si ya no hay verdades absolutas, entonces solo quedan interpretaciones. Con ello Nietzsche quiere demoler todo el edificio de la metafísica occidental, en pie desde Platón (Mèllich, 2008, p. 36).
Para Nietzsche, a juicio de Mèllich, "cualquier unidad es falsa"; en lugar de la unidad coloca "la diferencia y la fragmentariedad que dividen el saber y el hombre mismo en una salvaje multiplicidad" (Mèllich, 2008, p. 36). Tradicionalmente, continúa Mèllich (2008), la ontología de Platón, la epistemología de Descartes y la moral de Kant, por ejemplo, han necesitado fabricar un punto arquimédico (un punto fijo y seguro) del conocimiento y de la acción para obtener seguridad en el pensar, en el decir y en el hacer; esto, sin embargo, es una falacia para Nietzsche.

En unos fragmentos póstumos del gran exponente del nihilismo, Mèllich observa que se encuentran ideas como las siguientes: 1) critica al positivismo cuando este afirma que 'solo hay hechos', cuando se fija en el fenómeno; frente a esto Nietzsche habría afirmado que no hay exactamente hechos, como sostiene el positivismo, sino solo interpretaciones; no podemos determinar ningún 'factum en sí', habría enfatizado; 2) ante afirmaciones que sostienen que 'todo es subjetivo', Nietzsche las habría refutado diciendo que esa aserción es ya una interpretación, que el 'sujeto' no es nada dado, sino algo inventado que añadimos, que ponemos detrás. ¿Es al cabo necesario poner al interpretador detrás de la interpretación? Esto es ya una ficción, una hipótesis, habría rematado el gran pensador alemán decimoLas cursivas son del autor. 
nónico. En suma, Nietzsche ${ }^{5}$ habría establecido algo muy caro a la mentalidad posmoderna: no hay hechos, solo interpretaciones (Mèllich, 2008).

En La gaya ciencia, en el aforismo 125, Nietzsche afirma que 'Dios ha muerto'...

¿No habéis oído hablar de ese loco que encendió un farol en pleno día y corrió al mercado gritando sin cesar: "Busco a Dios!, ¡Busco a Dios!”. Como precisamente estaban allí reunidos muchos que no creían en dios, sus gritos provocaron enormes risotadas. ¿Es que se te ha perdido?, decía uno. ¿Se ha perdido como un niño pequeño?, decía otro. ¿O se ha escondido? ¿Tiene miedo de nosotros? ¿Se habrá embarcado? ¿Habrá emigrado? - así gritaban y reían alborozadamente. El loco saltó en medio de ellos y los traspasó con su mirada. "¿Qué a dónde se ha ido Dios? -exclamó-, os lo voy a decir. Lo hemos matado: ¡vosotros y yo! Todos somos su asesino. Pero ¿cómo hemos podido hacerlo? ¿Cómo hemos podido bebernos el mar? ¿Quién nos prestó la esponja para borrar el horizonte? ¿Qué hicimos cuando desencadenamos la tierra de su sol? ¿Hacia dónde caminará ahora? ¿Hacia dónde iremos nosotros? ¿Lejos de todos los soles? ¿No nos caemos continuamente? ¿Hacia delante, hacia atrás, hacia los lados, hacia todas partes? ¿Acaso hay todavía un arriba y un abajo? ¿No erramos como a través de una nada infinita? ¿No nos roza el soplo del espacio vació? ¿No hace más frío? ¿No viene de continuo la noche y cada vez más noche? ¿No tenemos que encender faroles a mediodía? ¿No oímos todavía el ruido de los sepultureros que entierran a Dios? ¿No nos llega todavía ningún olor de la pu- trefacción divina? ‘También los dioses se pudren! ¡Dios ha muerto! ¡Y nosotros lo hemos matado! (...) Todavía se cuenta que el loco entró aquel mismo día en varias iglesias y entonó en ellas su Requiem aeternan deo. Una vez conducido al exterior e interpelado contestó siempre esta única frase: "¿Pues, qué son ahora ya estas iglesias, más que las tumbas y panteones de Dios?" (Nietzsche, F., s. f.).

¿Qué quiere decir el gran pensador con esta afirmación? Mèllich nos aclara el enigma: "La muerte de Dios es la metáfora que Nietzsche utiliza para expresar el fin de la creencia en los valores últimos y supremos de la existencia. (...)" (Mèllich, 2008, p. 36).

¿Qué más podemos decir de la 'muerte de Dios'? Que la metafísica ya no puede encontrar una nueva fundamentación, un nuevo principio metafísico; que Dios no es ya una garantía de ninguna interpretación de lo real y, entonces, es posible interpretar el mundo de diferentes maneras; que no hay una interpretación única y última de la realidad. ${ }^{6}$ Entonces, para Nietzsche, el mundo no está sujeto a una sola interpretación (Mèllich, 2008, p. 36).

5 A juicio de quien escribe estas páginas, una de las críticas más demoledoras de Nietzsche a la filosofía y al Cristianismo reside en la crítica moral, contenida en Genealogía de la moral y Más allá del bien y del mal, donde manifiesta las relaciones de dominación que se esconden tras los conceptos morales, la plasmación de estas relaciones en la forma lingüística de la moral, donde conceptos como bueno y malo, entre otros, según él, no son más que patrañas que representan relaciones de poder.

6 Esto último tendrá graves repercusiones en cuanto a la moral, como ya lo advirtió Ė. Durkheim a inicios del siglo XX. 
El que Dios haya muerto indica también que el mundo suprasensible - "la ilusión de los trasmundos”, le llama Mèllich (2008)pierda fuerza. Recordemos que esta 'ilusión' fue la base de todo el sistema filosófico de Platón -de su filosofía política, de su estética, de su pensamiento pedagógico, de su filosofía moral, etc.-, un mundo inteligible, real, accesible a la razón, y un mundo sensible, el mundo concreto, del devenir, de la apariencia, que no es la verdadera realidad; pero este no es solo el pensamiento de Platón, sino de todos sus seguidores a lo largo de la historia. A esta 'ilusión' de Platón, Nietzsche la llama una sublime patraña, y viejo loco al padre del idealismo.

Si Dios ha muerto, entonces, todo es contingente; no queda nada a qué atenerse, nada seguro. El mismo lo dirá afirmando las consecuencias morales de esta muerte: si Dios ha muerto, no hay ninguna garantía absoluta de la moral, ni normas morales absolutamente válidas. Esto se parece mucho a lo dicho por su contemporáneo, Dostoyevsky, cuando afirmaba que "si Dios ha muerto, todo está permitido.”

Mèllich (2008) plantea las consecuencias de la muerte de Dios de la manera siguiente: no hay ni arriba ni abajo, ya no hay horizonte. No hay puntos de referencia, no hay centros, ni valores últimos ni absolutos respecto a los que el ‘yo' pueda construir su identidad y dar sentido a la vida. Esto, para Mèllich, no tiene nada que ver con la falta de fe o con el ateísmo, y tampoco debe interpretarse en clave teológica, como lo hizo en los años 60 la así llamada teología de la muerte de Dios. Lo que Nietzsche pone de manifiesto es que la verdad del mundo suprasensible se ha desvanecido, y que el ser humano es abandonado a sus propias fuerzas; queda huérfano.

Esto es en definitiva el nihilismo, afirma Mèllich (2008); y ello no es ninguna propuesta de Nietzsche, sino un análisis del recorrido de la metafísica occidental. Los valores supremos son los errores supremos. Verdad, bien, belleza pierden su carácter vinculante. ${ }^{7}$ $¿$ ¿Puede seguirse hablando de valores supremos?, ¿tiene sentido?, ¿puede seguir siendo válido hablar de utopías, de sueños, etc.?

Este nuevo contexto cultural, que conduce a un relativismo en casi todas las dimensiones de la vida, explica en buena parte lo difícil que es la actividad educativa en el mundo actual. Muy pocos pedagogos disentirán del postulado que afirma que educar hoy es más difícil que en el tiempo en que ellos fueron educados, y esta dificultad es explicable porque la educación es una actividad que requiere asideros morales, algunos puntos firmes y, sobre todo, necesita de la utopía, que es profundamente minada en la posmodernidad.

7 ¿Cómo se manifiesta esto por ejemplo en la literatura? Una ilustración de ello podría ser la así llamada estética de la recepción; en la ética se expresa como un subjetivismo y un relativismo axiológicos; en la religión, diciendo que todas hablan de Dios y todas son buenas, etc. En el matrimonio, en la pérdida de valor del mismo y en el trastocamiento de la idea tradicional de familia y de pareja. 


\section{El èthos moderno}

Tras este comentario crítico a la moralidad posmoderna, Bauman resume lo que es la ética posmoderna en relación con la moderna:

Sugiero que la novedad del enfoque posmoderno de la ética consiste, ante todo, no en hacer a un lado las preocupaciones morales modernas características, sino en rechazar las formas modernas típicas de abordar los problemas morales; esto es, responder a los retos morales con normas coercitivas en la práctica política, así como en la búsqueda filosófica de absolutos, universales y sustentos de la teoría. Los grandes problemas éticos -derechos humanos, justicia social, equilibrio entre la cooperación pacífica y la autoafirmación- no han perdido vigencia; únicamente es necesario verlos y abordarlos de manera novedosa (Bauman, 2005, pp. x-xi).

El problema ético posmoderno para Bauman, luego, no difiere demasiado del moderno en cuanto a sus tópicos, sino en dos aspectos: la forma de abordar los problemas morales y el cese de búsqueda de universales y absolutos como garantía moral.

$\mathrm{Al}$ referirse al pensamiento y a la práctica moral de la modernidad, Bauman (2005, pp. xviii) afirma que estos eran animados "por la creencia en la posibilidad de un código ético no ambivalente y no aporético". ${ }^{8} \mathrm{La}$ posmodernidad, por su parte, se caracterizaría por la incredulidad frente a esa creencia:

La incredulidad en esa posibilidad es justamente lo posmoderno, «pos» no en el sentido "cronológico» (de desplazar y sustituir la modernidad, de nacer al momento en que la modernidad termina una vez que queda indefensa), sino en el sentido de que a manera de conclusión, de mera premonición, los esfuerzos que la modernidad ha realizado durante tanto tiempo estaban desviados, erigidos sobre bases falsas y destinadas, tarde o temprano, a agotarse. (...) (Bauman, 2005, p. xix).

Bauman, entonces, piensa que la propia modernidad demostró su imposibilidad, lo vano de sus esperanzas y el desperdicio de sus esfuerzos. A ese código ético que la modernidad creyó encontrar, con fundamentos universales e inamovibles -empresa imposible para el autor-, este lo llama código ético a prueba de tontos. (Bauman, 2005, p. xix). La posmodernidad, en este sentido, puede ser entendida como una crítica a esas ambiciones modernas, cuyas consecuencias son el objeto de estudio del autor.

Con la posmodernidad, según Bauman (2005), adviene un pluralismo que rompe el molde de la tradición, escapa de controles y se libera del monopolio ético de la Iglesia. Esto se da frente a pretensiones de la ética moderna, iniciada en los albores del Renacimiento, que rechazaba la ambivalencia de juicios morales y pensaba que su código debía ser obedecido por cualquier persona moral. Este pluralismo fue recibido con alegría

8 Las cursivas son del autor. 
por la minoría pensante, sobre todo porque era observable el efecto emancipador del pluralismo. Con razón, Carr (1999, pág. 92), gran estudioso de la educación, afirma que "el culto a la diversidad es la característica esencial de la posmodernidad".

Los filósofos modernos pensaron los alcances de su ética de la siguiente manera:

(...) La ética de los filósofos sustituiría la Revelación de la Iglesia, con la pretensión radical e inexorable de validez universal. De esta manera, los filósofos sustituirían a los clérigos en su calidad de guías espirituales y guardianes de las naciones (Bauman, 2005, p. 11).

Bauman piensa que la modernidad solo reconocía como morales las reglas que pasaban la prueba de los principios universales, extemporáneos y extraterritoriales. Esta pretensión conllevó, continúa, al desconocimiento de las pretensiones comunitarias, temporales y territoriales de hacer juicios morales autorizados, anota. Además, añade, la modernidad consideró cualquier relatividad como un estorbo para su proyecto. La universalidad moral era el ideal, el sueño y el horizonte de la historia. La universalidad, prosigue, era el destino último. En este sentido, afirma, la modernidad podría caracterizarse de manera conspicua como una época que cree en el futuro y construye sueños alrededor del mismo.

\section{El èthos posmoderno}

Zygmunt Bauman (2005, p. vii) distingue entre ética posmoderna y moralidad posmoderna. Por esta última entiende la realización de un inventario de "problemas morales que hombres y mujeres del mundo posmoderno intentan resolver". Estos problemas, refiere el autor, "eran desconocidos o pasaban inadvertidos para generaciones anteriores"; aunque también, reconoce, en la moralidad posmoderna aparecen "problemas antiguos con nuevas facetas”. ¿Cuáles son esos problemas? Pronto lo veremos.

Por ética posmoderna-objeto de su estudio citado arriba-, en cambio, el gran sociólogo polaco entiende lo siguiente: como resultado de que la era moderna haya llegado a su "etapa autocrítica, autodenigrante y, en muchos sentidos, autodesmanteladora (proceso que el concepto de «posmodernidad» pretende abordar y transmitir), los diversos caminos que antes seguían las teorías éticas", prosigue el autor, "acabaron por volverse cada vez más una especie de callejón sin salida, aunque también abrían la posibilidad de una comprensión radicalmente novedosa de los fenómenos morales" (Bauman, 2005, p. viii).

Según el autor, en la posmodernidad se celebra la "debacle de lo ético" y hay, además, una "sustitución de la estética por la ética". En la posmodernidad, continúa, "la ética se denigra o se considera una de las restricciones típicas de la modernidad, cuyas cadenas finalmente han sido rotas y echadas al basurero de la historia" (Bauman, 2005, p. viii).

Para ilustrar lo anterior, Bauman refiere el ejemplo de la obra de Gilles Lipovetsky, El crepúsculo del deber. En dicho libro su autor afirma que hemos entrado en una época 
posdeóntica. En esta época, la posmoderna, nuestra conducta se ha liberado de los últimos vestigios de los opresivos deberes infinitos, mandamientos y obligaciones absolutas. Además, en esta época se ha deslegitimado la idea de autosacrificio; la gente ya no se siente perseguida ni está dispuesta a hacer un esfuerzo por alcanzar ideales morales; los políticos, continúa resumiendo Bauman, han acabado con las utopías y los idealistas de ayer se han convertido en pragmáticos. El autor cierra su resumen de la obra de Lipvetsky con las siguientes palabras: "vivimos en la era del individualismo más puro y de la búsqueda de la buena vida, limitada solamente por la exigencia de tolerancia" (Bauman, 2005, p. ix).

En definitiva, en la posmodernidad hemos entrado en lo que muchos autores -incluidos Bauman, Lipevetsky y otros- llaman época posdeóntica, posterior al deber, en la que, como dice Bauman, "apenas se admite un vestigio de moralidad", pero de una "moralidad minimalista". (Bauman, 2005, p. ix). Por su parte, Bilbeny (1997, p. 184) expresa lo anterior con más radicalidad, al observar que en la posmodernidad (era digital, le llama) "todo está cambiando, incluso los hábitos y las creencias que parecían más arraigados". Esta revolución, como él la llama, se expresa específicamente en las "mutaciones en el mundo del trabajo, la familia y la educación, o la paulatina conversión de la política y la cultura en espectáculo, donde también la religión tiene su cuota"; además, "se encuentra desde luego la ética". (Bilbeny, 1997, p. 184)
Lo que Lipovetsky hace, a juicio de Bauman, es describir las conductas prevalentes en la posmodernidad, de las que afirma que debe "aplaudirse su llegada". De manera acertada, Bauman afirma que "describir conductas prevalentes no significa hacer un juicio moral". Añade que un "pensamiento crítico se rehúsa a aceptar que algo está bien solo porque existe; tampoco dará por un hecho que lo que hacen los seres humanos es solo lo que piensan que hacen o cómo narran lo que han hecho". (Bauman, 2005, p. x).

Buena parte de lo que caracteriza a la posmodernidad es la presencia de una moralidad sin un código ético, según Bauman (2005, pp. 20-22): vivimos una moral sin principios, una moral sin fundamentos, la que pretende demostrar que se puede vivir sin saber cuáles son los principios rectores o los fundamentos sin los cuales aparentemente no se podría hacer el bien. Estamos, entonces, para Bauman, en una desregulación de la conducta humana, sin un código ético estricto y abarcador. Relacionado con lo anterior, el autor nos dice qué significa ser posmoderno:

Ser conscientes de que ésta es la verdad $-O$ al menos intuirlo o pretender saberlo- es ser posmoderno. Podríamos decir que la posmodernidad es una modernidad sin ilusiones; el anverso sería que la modernidad es una posmodernidad que se niega a aceptar su propia verdad. (...) (Bauman, 2005, p. 22).

Para Bauman (2005, p. 112), "Una de las características más notorias de la intimidad posmoderna -esto es el tipo de intimidad 
que buscan y practican hombres y mujeres que llevan un estilo de vida posmodernoes que tiende a liberarse de las compulsiones morales que simultáneamente motivan y restringen las relaciones amorosas Yo-Tú". Esta conducta ha comenzado a mostrar su carácter autodestructor de las relaciones interpersonales, tal como se puede verificar en las relaciones líquidas, inestables y pasajeras se enarbolan la liberación posmoderna de grilletes y ataduras morales, y luego se cae en el desencanto y la frustración.

Una pregunta válida a esta altura de la exposición es si la posmodernidad destruyó a la modernidad. Bauman (2005, p. 257) piensa que solo destruyó las pretensiones de la modernidad de construir una legislación ética universal:

¿Acaso la condición posmoderna es un avance frente a los logros morales de la modernidad? La posmodernidad ha destruido las ambiciones modernas de contar con una legislación universal y sólidamente sustentada, pero ¿habría acabado también con las pocas oportunidades que tiene la modernidad de mejorar moralmente? En el mundo de la ética, ¿se considera a la posmodernidad un paso adelante o un retroceso?"

F. Lyotard (1994) afirma que la característica de la existencia moderna fue «vivir con un proyecto», y que ese gran proyecto, que es el centro de la inquietud moderna, fue la idea de la emancipación. Esa idea de proyecto, en cambio, desaparece con la posmodernidad, donde el individuo y la sociedad carecen de un horizonte utópico que, como afirma Bauman (2005), ha sido liquidado, y cuya muerte es imputable principalmente a los políticos.

\section{El tipo posmoderno: ¿nómada o vagabundo?}

¿Cómo es moralmente el ser humano posmoderno? Bauman sostiene que la condición moral de hombres y mujeres posmodernos podría parecerse a la situación del nómada, o bien a la del vagabundo.

¿Cuál es la condición del nómada? Veamos la descripción que del mismo nos ofrece Bauman (2005). A diferencia de los colonos, los nómadas están en movimiento, y a diferencia de los peregrinos, los nómadas no tienen un «destino final» que marque de antemano su itinerario, como tampoco tienen un lugar privilegiado rumbo al cual todos los sitios que atraviesan no sean sino estaciones. Además, los nómadas se mueven de un lugar a otro en una sucesión estrictamente regular. Los nómadas, concluye el autor, no son la metáfora adecuada para expresar la condición de los hombres y mujeres en la posmodernidad.

El autor (Bauman, 2002) encuentra, no obstante, otra metáfora que considera más adecuada para expresar la condición moral posmoderna. Se trata de la metáfora del vagabundo. Este no sabe cuánto tiempo permanecerá donde se encuentra hoy, y generalmente no depende de él cuando terminará su estancia. Al moverse, el vagabundo fija el destino conforme avanza y va leyendo las señalizaciones en el camino, mas ni 
siquiera entonces está seguro si se detendrá, y durante cuánto tiempo, en la siguiente parada. Lo que sabe, añade Bauman, es que posiblemente la próxima parada en su caminar será temporal.

¿Por qué se mueve el vagabundo o qué lo motiva a moverse? Bauman (2005) relata que lo que mantiene al vagabundo en movimiento es la desilusión con el lugar donde acaba de estar y la esperanza siempre latente de que el siguiente lugar a visitar, o quizás el que siga después de este, esté libre de los defectos que le repulsaron en los lugares que probó.

El vagabundo se guía, continúa Bauman, siempre animado por una esperanza no probada; es impulsado por la esperanza frustrada... "el vagabundo es un peregrino sin destino, un nómada sin itinerario", concluye el autor (Bauman, 2005, p. 280).

Bilbeny (1997, p. 168), quien con toda probabilidad hace un comentario sarcástico a la métafora de Bauman, expresa que seguramente "en alguna parte se dará refugio al caminante o por lo menos razón de su caminar".

Es obvio que el vagabundo vive en incertidumbre. En la Modernidad líquida, Bauman (2003, p. 67) afirma que la incertidumbre moral en la modernidad no era el desconocimiento de los fines, sino la incertidumbre de los medios; contrario a ello, en la posmodernidad se trata de otra incertidumbre, totalmente nueva:

(...) Ya no se trata de evaluar - sin completo conocimiento- los medios (aquellos disponibles y los que se consideran necesarios y deben conseguirse) para lograr el fin deseado. Se trata más bien de considerar y decidir, ante los riesgos conocidos o supuestos, cuál de los muchos fines "al alcance" (es decir, los que pueden ambicionarse razonablemente) resulta prioritario. Dados los medios disponibles y tomando en cuenta sus magras posibilidades de utilidad verdadera" (Bauman, 2003, p. 67).

El autor cierra su Ética posmoderna con las siguientes palabras que resuenan en no pocas conciencias críticas:

La responsabilidad moral es la más personal e inalienable de las posesiones humanas, y el más preciado de los derechos humanos. No puede ser arrancada, compartida, cedida, empleada ni depositada en custodia. (...) (Bauman, 2005, pág. 293)

\section{¿Qué hacer para superar el ēthos posmoderno?}

Bilbeny (1997) hace una propuesta para la superación de los dilemas morales posmodernos, la que podría resumirse en la necesidad de fomentar lo que él llama un minimo común moral, no de una ética de máximas. Este planteamiento consiste en lo siguiente: la ética apropiada para nuestro tiempo debe asumir los cambios y estar dispuesta al cambio. Este cambio pasa por adoptar lo que él llama un punto de vista cognitivo, lo que en lenguaje más llano quiere decir que en la actualidad es muy difícil pensar que cambiando hábitos y creencias -que requieren mucho tiempo 
para arraigar- se operará una transformación moral; en cambio, un desarrollo cognitivo del individuo puede suplirlos. Además de ello, el autor piensa que este punto de vista cognitivo debe ir acompañado de un apoyo de la sensibilidad y del rescate de los sentidos, en particular el de la vista y el del tacto. Según él, este último rescate hace de la ética una tarea entre seres vivos y presentes, más que un cálculo estratégico.

El autor (Bilbeny, 1997, p. 171) propone tres principios orientadores que, según él, deberían estar presentes en su ética desde el punto de vista cognitivo: i) pensar por uno mismo (autonomía moral), ii) imaginarse en el lugar del otro a la hora de pensar, iii) pensar de forma consecuente con uno mismo.

Mi punto de vista, en cambio, es como propongo a continuación. Dado que la posmodernidad puede entenderse, en buena medida, como una condición moral que vive la mayoría de seres humanos en la sociedad actual, enfrentar esta situación exige una respuesta moral; aunque debemos evitar el riesgo de caer en un espinosismo, que pretendería reducir los problemas de la posmodernidad a una cuestión moral. Recordemos que, para Bauman (2005), lo que caracteriza a la posmodernidad es, en gran parte, la presencia de una moralidad sin un código ético; lo que describe de la siguiente manera: vivimos una moral sin principios, una moral sin fundamentos, la que pretende demostrar que se puede vivir sin saber cuáles son los principios rectores o los fundamentos sin los cuales aparentemente no se podría hacer el bien. En otras palabras, la condición moral pos- moderna vive en un estado de desregulación de la conducta humana, sin un código ético estricto y abarcador. Esto ha sido llamado por algunos como una época posdeóntica.

Visto desde esta perspectiva, luego, el problema de la posmodernidad es un problema ético y un problema moral. En cuanto problema ético, es necesario rehacer el discurso ético; pero este debe hacerse sin desechar el discurso ético de la modernidad, sino aprovechando lo mejor de sus logros teóricos. El discurso de la modernidad nos enseñó que el proyecto de futuro es necesario para la acción, además de indicarnos que una acción es moralmente buena cuando es universalizable. Hoy es más necesario un discurso ético y una práctica moral universales - sin que ello se confunda con elaborar un código ético a prueba de tontos, como sarcásticamente critica Bauman-, puesto que los grandes desafíos y problemas de la humanidad son universales: la degradación del medio ambiente y el imperativo de revertir esta tendencia para hacer posible la vida a generaciones futuras, detener el consumismo desenfrenado e insolidario, devolver la esperanza a miles de millones de seres humanos que viven en condiciones inhumanas, democratizar la sociedad, el Estado y las principales instituciones de la sociedad, crear una cultura moral en la sociedad. Esto no puede ser posible sin la construcción de un proyecto histórico común, aunque esto sea una idea de la modernidad; en otras palabras, no puede haber un discurso ético coherente sin una utopía, aunque no debemos confundir esta misma con ilusiones y delirios, sino que se trata de una utopía activa, como Emmanuel Levinas 
la llama, la cual se caracteriza por su capacidad para generar una acción moral.

La posmodernidad, decíamos, es también un problema moral, esto es, hay un ethos posmoderno. Este bien puede ser descrito con la imagen del vagabundo de Bauman. Existe un conjunto de prácticas que se han legitimado porque funcionan, porque todos las practican o porque dan buenos resultados. El individualismo exacerbado ha llegado a tal grado que se piensa que cada quien debe inventar sus propios imperativos, que todo vale y que todo es permitido. Hay una desregulación casi total de la acción y se cree que no es posible construir una idea del bien válida para regular la conducta.

Parece ser válido considerar, entonces, la mentalidad posmoderna un ethos, que bien podríamos describir así: se trata de un relativismo moral y de un desarraigo; cada quien se da sus propios imperativos; las relaciones interpersonales se vuelven líquidas, para usar la feliz expresión de Bauman (muchos estudiosos afirman que relaciones estables y duraderas suelen hacer más felices y realizados a los seres humanos); se reducen los problemas del mundo a problemas de género, de identidad sexual, de emociones o de subjetividad. ${ }^{?}$

Es cierto que una propuesta moral no puede ir ya por caminos que han mostrado su invalidez. Por ejemplo, la moral no puede reducirse a sermones dominicales aburridos, a la mera inculcación y a la prédica, o a lo que algunos han dado en llamar cruzada de valores. Por otro lado, la acción moral hoy es más compleja: la idea de prójimo como alguien a quien afecta mi acción no puede ser vista con la perspectiva de vecindad y de visibilidad del daño o del bien moral, y las prácticas morales necesitan ser guiadas por un pensamiento autónomo y por la educación. A este propósito, me parecen acertadas las palabras de F. Vallaeys (s. f.) cuando, a manera de ejemplo, sostiene la necesitad de una cierta ilustración para la acción moral:

(...) sólo el conocimiento de los problemas ecológicos puede hacernos valorar la conservación de los equilibrios ecosistémicos y desarrollar una ética personal ecológica. Otro ejemplo es la aceleración de los cambios históricos en la era de la ciencia, que nos plantea regularmente nuevos conflictos éticos inexistentes anteriormente, cambiando así la "agenda ética". También es conocida la estrecha relación entre el nivel educativo y la complejidad y calidad de los juicios morales producidos.

Además de todo lo anterior, si queremos unas prácticas morales racionales y autónomas, será necesaria una transformación del pensamiento y de la educación, puesto que como varios estudiosos han demostrado, los cambios de la acción humana están

9 Este diagnóstico de los problemas del mundo es ridículo, por no decir absurdo. Stephen Hawking, el gran astrofísico inglés, contradiría esto cuando recientemente afirmó que la humanidad corre mucho peligro de causar su propia destrucción mediante una guerra nuclear, el calentamiento global, los virus creados con ingeniería genética y el actual desarrollo en la ciencia y la tecnología. 
muy ligados a los cambios de pensamiento -aquello que Platón y luego el Cristianismo llamaron metanoia, cambio de mente-, al desarrollo intelectual, a la educación familiar, a los niveles de educación, a las prácticas que se dan en la vida social y a tantas otras variables. Aunque todo esto sea cierto, la práctica moral exige una conciencia libre y una responsabilidad individual; no es reductible a lo social. En suma, existe la necesidad de nuevas prácticas sociales, políticas, comunales, vecinales, familiares; necesidad de nuevos discursos en el plano moral, político, religioso, familiar, ambiental; esto es, nuevas teorías y nuevas prácticas.

Lo anterior incluye la necesidad de una educación moral en la escuela, pero también en otros espacios de la vida social y, en general, en todas las prácticas sociales; y no se trata de un simple respeto a la diversidad - o un culto a la misma-, o de aplicar la así llamada regla de oro en la vida cotidiana. Es necesaria una moral estudiada, cultivada, autónoma y pensada; la rectitud de la acción tiene como uno de sus fundamentos sólidos el pensamiento adecuado; un desorden mental suele traducirse en un desorden moral. Parece que Sócrates tenía razón cuando en el Protágoras de Platón nos enseña que en el fondo de la acción moralmente mala subyace la ignorancia.

En todo caso, hablar de èthos posmoderno no puede limitarse a describir la práctica moral actual de la mayoría de la humanidad, describir sus vicios y virtudes; lamentar el carácter pasajero, desarraigado, líquido, de sus relaciones interpersonales y afectivas; exponer su héxis y su carácter; para luego afirmar que así son las cosas y que no pueden ser de otra manera. En suma, el discurso ético no puede reducirse a constatar su existencia. Bauman (2005) es muy tajante cuando afirma que esto es insuficiente y que algo no está bien simplemente porque existe. Entonces, es necesaria la formación de un nuevo èthos contrapuesto a lo que hemos descrito como èthos posmoderno, el que debe incluir algunas de las ideas trazadas más arriba sobre problemas éticos y problemas morales, además de indicarnos qué debe entenderse hoy por una vida moralmente recta y qué prácticas y discursos pueden contribuir a la formación del èthos.

$\mathrm{Al}$ afirmar el aporte que puede hacer la filosofía moral a la acción somos conscientes de que la filosofía ética no crea el èthos, pero por tratarse de una filosofía práctica, la misma bien podría inspirar la búsqueda de nuevos caminos para transformar la moral y ayudar a que las instituciones y las fuerzas implicadas en la formación moral y en su transformación encuentren nuevas ideas para su práctica.

En sociedades antiguas y premodernas, lo anterior estaba suficientemente claro. Entre los griegos, por ejemplo, no había rectitud moral que no incluyera el pagar el debido respeto a los dioses, el interés por los asuntos públicos (político) y la generosidad con los que padecen necesidades, como afirma Aristóteles. En De oratore, de Cicerón, igualmente, se creía que la perfección del ser humano se alcanzaba al llegar a ser vir bonus et peritus dicendi (hombre bueno y experto en el discurso), lo que a veces el autor llama 
vir eloquens (hombre elocuente). Actualmente no existen consensos sobre lo que es el bien moral y la recta actuación, pero tampoco sobre la acción moralmente perversa; la fragmentación del pensamiento y de la acción, además del juicio moral torcido, nos están llevando al descalabro moral sin precedentes. No puede cada quien, en su subjetividad, decir en qué consiste su bien moral, ya Aristóteles decía en su Ética Nicomáquea que el camino para actuar bien es uno; en cambio, son miles los caminos para hacer el mal.

\section{Tercera parte: conclusión}

Después de este recorrido por los conceptos de ética y de moral, así como de modernidad y posmodernidad, parece ser válido y legítimo considerar a esta última de una manera doble: por un lado, se trata de una condición moral de los seres humanos en este momento histórico y cultural; por otro, el concepto se refiere a una teoría que pretende explicar esta condición, a la que justo llama posmodernidad. Dicha condición puede ser descrita de múltiples maneras: como incredulidad frente a los metarrelatos, como un relativismo moral exacerbado y desregulado, o como fin de la idea de un proyecto utópico que genere, inspire y regule la acción moral.

La descripción general de la condición posmoderna que hacen los teóricos de la posmodernidad, y que no pocos defienden como el fin de la historia, puede, sin embargo no ser muy rigurosa. En varios países latinoamericanos, y concretamente en El Salvador, por ejemplo, a la par de esa mentalidad y èthos posmoderno coexisten, no obstante, mentalidades premodernas y modernas: masas de campesinos y marginados que siguen creyendo y practicando la magia, personas que siguen creyendo en el metarrelato cristiano, personas que creen en la validez, todavía, de normas de conducta universalmente válidas y, no pocas de ellas, piensan que todavía es posible una emancipación y que la utopía sigue viva. En este sentido, también hay que relativizar la teoría de la posmodernidad y, del mismo modo, pensar que su práctica todavía no tiene universalidad.

En la posmodernidad el mundo intelectual y moral se atomiza y fragmenta, pero lo mismo sucede con las luchas sociales y el mundo de lo político. El ser humano se queda sin rumbo y sin dirección, sin un horizonte utópico que le oriente en su camino. Cada quien se da sus propios imperativos, como anunciaba Nietzsche en el siglo XIX. Las relaciones interpersonales se vuelven frágiles, pasajeras y líquidas; se desregulan todas las acciones humanas -todo vale; esto es, el menefreghismo, que pregonan no pocos italianos- y, como decía Bauman, la vida sexual queda libre de toda compulsión moral. Por eso es posible concebir la posmodernidad como un etthos, donde hay una pluralidad sin unidad o, en otras palabras, la multiplicidad sin el uno. Esta carencia del uno puede llevarnos al caos y a la autodestrucción.

Este èthos posmoderno o moral del nómada, como la llama Bauman, puede llevarnos a la autodestrucción. Por eso se hace necesario contraponer otro modo de entender la acción humana, alternativo al modo de ser 
posmoderno, y que he tratado de trazar en este escrito. No podemos limitarnos a describir el éthos posmoderno y celebrar la liberación de las ataduras morales, de la vigilancia religiosa y de toda cadena de la modernidad que nos impedía ser libres. Se debe ser demasiado ingenuo para celebrar esto; en realidad, yo no veo que debamos festejar nada al respecto. Solo las personas inteligentes piensan que la acción humana necesita regulaciones que vayan más allá del propio yo; las regulaciones morales nos hacen saber, justamente, que el mundo no es solo un yo, sino un tú y un nosotros; en este sentido nos limitan y nos abren posibilidades, al mismo tiempo.

\section{Referencias bibliográficas}

1. Abbagnano, N. (1989). Diccionario de filosofía. México: Fondo de Cultura Económica.

2. Aristóteles. (1985). Ética Nicomáquea y Ética Eudemia. Madrid: Gredos.

3. Bauman, Z. (2003). La modernidad líquida. México: Fondo de Cultura Económica.

4. Bauman, Z. (2005). Ética posmoderna. México: Siglo XXI Editores.

5. Bilbeny, N. (1997). La revolución en la ética. Hábitos y creencias en la sociedad digital. Barcelona: Anagrama.

6. Carr, W. (1999). Educación y democracia ante el desafío posmoderno. Volver a pensar la educación. Tomo II, 96-111. Madrid: Ediciones Morata.

7. Cicerón. De oratore. Disponible en: http://históricodigital.com

8. Eliade, M. (1980). El mito del eterno retorno. Arquetipos y repetición. Madrid: Alianza Editorial.

9. Heródoto. (1998). Los nueve libros de la historia. México: Editorial Porrúa.

10. Hesiodo. (1982). Teogonía, los trabajos y los días, y el escudo de Heracles. México: Editorial Porrúa.
11. Liddell, H. G. \& Scott, R. (1966). A Greek-English Lexicon. Oxford: Clarendon Press.

12. López Aranguren, J. L. (1998). Ética. Barcelona: Ediciones Altaya.

13. Lyotard, J. F. (1991). La condición posmoderna. Informe sobre el saber. Madrid: Ediciones Cátedra.

14. Lyotard, J. F. (1994). La posmodernidad explicada a los niños. Barcelona: Editorial Gedisa.

15. Mèllich, J. C. (2008). "Filosofía y educación en la postmodernidad". En Hoyos Vásquez, G. (ed.), Enciclopedia iberoamericana de filosofía (pp. 35-53). Madrid: Editorial Trotta.

16. Mir, J. M. (ed.). (1990). Diccionario ilustrado latino español, español-latín. Barcelona: Bibliograf.

17. Nietzsche, F. (s. f.). La gaya ciencia. Recuperado de www.edu. mec.gub.uy.

18. Platón (1991). Diálogos. México: Editorial Porrúa.

19. Sánchez Vásquez, A. (1984). Ética. México: Grijalbo.

20. Vallaeys, F. (s. f.). El desafío de enseñar ética en la universidad. Recuperado de http://www.upch.edu.pe/rector/durs/images/ Biblio/MarcoConceptual/EnsenarEticaRS/eldesafiodeensenareticaenlauniversidad.pdf 